\title{
Financial Constraints, Competition, and Hedging in Industry Equilibrium
}

\author{
TIM ADAM, SUDIPTO DASGUPTA, and SHERIDAN TITMAN*
}

\begin{abstract}
We analyze the hedging decisions of firms, within an equilibrium setting that allows us to examine how a firm's hedging choice depends on the hedging choices of its competitors. Within this equilibrium some firms hedge while others do not, even though all firms are ex ante identical. The fraction of firms that hedge depends on industry characteristics, such as the number of firms in the industry, the elasticity of demand, and the convexity of production costs. Consistent with prior empirical findings, the model predicts that there is more heterogeneity in the decision to hedge in the most competitive industries.
\end{abstract}

*Adam is from the MIT Sloan School of Management, Dasgupta from the Hong Kong University of Science \& Technology (HKUST), and Titman from the University of Texas. We are grateful to Axel Adam-Müller, Söhnke Bartram, Nittai Bergman, Dirk Jenter, Peter Mackay, Gordon Phillips, James Vickery, Keith Wong, and an anonymous referee for valuable suggestions that greatly improved the paper. We would also like to thank seminar participants at HKUST, MIT, National University of Singapore, Tel Aviv University, University of Mainz, and the annual meetings of the American, European, and Western Finance Associations for their comments and discussions. Any remaining errors are our own. 
Risks have costs as well as benefits. The costs have been the focus of a growing literature on corporate risk management and hence are well understood. ${ }^{1}$ In contrast, the idea that risk can also be beneficial has been recognized in the real options literature but has largely been ignored in the risk management literature.

The objective of this paper is to analyze the hedging decisions of firms that take into account both the costs and the benefits of their risk exposures. To do so we develop a model in the spirit of Froot, Scharfstein, and Stein (1993) (henceforth, FSS). FSS assume that internal funds are less costly than external funds. Consistent with this view, we consider the extreme case in which firms must rely solely on internal funds to finance their investments. In contrast to FSS, however, we model a firm's output decision explicitly. In particular, we assume that firms have the flexibility to adjust their output levels in response to realized production costs after making their investment choices. Within this setting, the volatility of cash flows, which affect investment and in turn production costs, can benefit firms that have the flexibility to produce more when costs are low and less when costs are high. We show that because of this flexibility, a firm's profit function can be convex in investment, which provides financially constrained firms an incentive not to hedge.

A further contribution of our model is that it analyzes how these incentives affect firms' risk management decisions within the context of an industry equilibrium in which the equilibrium price is determined endogenously. Since the equilibrium output price is a function of aggregate investment and hedging decisions, a firm's risk management choice is affected by the investment/hedging decisions of other firms in the industry. Specifically, firms gain more from additional investment when other firms in the industry invest less, which implies 
that a firm has an incentive to make risk management choices that transfer cash flows to those states in which its competitors are relatively cash constrained. This in turn implies that an individual firm's incentive to hedge increases as more firms in the industry choose not to hedge and vice versa. As a result, an industry equilibrium can exist in which some firms hedge and others do not, even though all firms are ex ante identical.

The model developed in this paper is related to existing research that explores why similar firms in the same industry often choose different capital structures. In particular, our equilibrium analysis is related to Maksimovic and Zechner (1991), who show that exante identical firms may choose different debt-equity ratios, and De Meza (1986), who shows that otherwise identical firms may choose different production technologies in an industry equilibrium. Our model is also closely related to Shleifer and Vishny (1992), who examine how a firm's bankruptcy/liquidation costs depend on the financial health of its competitors. In the Shleifer and Vishny model capital structure choices are interdependent because the bankruptcy costs of an individual firm are lower if other firms within the same industry are financially healthy, and compete to buy the assets of failing firms. Similarly, the firms in our model have an incentive to generate cash flows in those situations in which other industry participants are financially constrained. ${ }^{2}$

Our model generates a number of predictions that relate industry characteristics to the fraction of firms that hedge. ${ }^{3}$ We find that in equilibrium approximately half of the firms use derivatives, while the other half do not. This is consistent with empirical studies that show that on average "hedging" and "not hedging" are equally common in the nonfinancial sector. ${ }^{4}$ The exact fraction of derivatives users depends on industry characteristics such as the number 
of firms in the industry (degree of competition), the elasticity of demand, the convexity of production costs, and market size. For example, our model implies that in industries with more competitors, steeper industry demand curves, and flatter marginal cost curves, there is more heterogeneity in firms' hedging choices, that is, the fraction of firms that hedge in industry equilibrium moves towards 50\% (the point of maximum heterogeneity). In addition, we find that larger market size results in a larger fraction of firms hedging in equilibrium.

These predictions are consistent with several empirical studies. Allayannis and Weston (1999), for example, find a positive correlation between mark-ups, which proxy for the degree of competition in an industry, and the extent of derivatives usage in that industry. Géczy, Minton, and Schrand (1997) find that in industries with many firms there is more heterogeneity in hedging decisions than in industries with relatively few firms. In addition, the idea that hedging choices affect product market prices is consistent with Nain (2004), who documents that output prices are less volatile in industries in which more firms hedge their foreign exchange rate risks.

The rest of the paper is organized as follows. In Section I, we outline the basic model and show that given our assumptions a firm's profit function is convex in investment and the equilibrium output price. In Section II, we consider the special case of a price-taking firm and illustrate how the profit function can be convex as well as concave in investment. Sections III and IV outline the subgame-perfect Nash equilibrium for our two-stage game. In Section V we discuss the comparative static results and in Section VI we consider several extensions of the model. Section VII discusses the empirical implications of the model and Section VIII concludes. 


\section{The Model}

Consider an industry with $n$ identical firms. At date 1, all firms receive identical but uncertain cash flows, which they can invest in productive capital that generates returns at date $2 .{ }^{5}$ At date 0 , firms decide whether or not to hedge their cash flows. If a firm does not hedge, the amount of funds available for investment at date 1 will be $y=\bar{y}+\epsilon$, where $\epsilon$ is a common shock to all firms and $E(y)=\bar{y}$. If a firm hedges, then the amount of funds available for investment at date 1 will be $y=\bar{y} \cdot{ }^{6}$

While firms can hedge at fair terms, we assume that they cannot raise external finance. Further, we assume that for all values of $y$, the marginal return to investment is higher than the opportunity cost of funds, which is normalized to one. This implies that firms will invest their entire cash flows, that is, $k=y$, where $k$ denotes a firm's investment. ${ }^{7}$

The above discussion is summarized in the following timeline of events:

$\mathrm{T}=0$ Firms only know the exogenous distribution of their cash endowments $y$ at $\mathrm{T}=1$, not the realization. Each firm decides whether or not to hedge their cash flows given the hedging strategies of all other firms. That is, hedging is determined within a Nash equilibrium.

$\mathrm{T}=1$ Cash flows are realized, and firms invest all of their cash flows. Each firm observes the investment decisions of all other firms. Firms then choose their outputs in the context of a Cournot equilibrium.

$\mathrm{T}=2$ Profits are realized. 


\section{A Technology and Production Costs}

The production of the firm's output requires two variable inputs, raw materials and labor, whose quantities are denoted respectively by $X_{1}$ and $X_{2}$. Capital investment $(k)$ decreases the requirement of materials $\left(X_{1}\right)$ per unit of output. The production function is assumed to be of the following form:

$$
q=\min \left[\gamma(k) X_{1}, X_{2}^{\frac{1}{2}}\right]
$$

where $\gamma(k)$ is an increasing and weakly concave function, that is, $\frac{d \gamma}{d k}>0$ and $\frac{d^{2} \gamma}{d k^{2}} \leq 0$. We choose this specification of the production function so that the associated cost function is convex in output, and an increase in investment $k$ reduces variable (and marginal) production costs.

The production function implies that producing $q$ units of output requires at least $\frac{1}{\gamma(k)} q$ units of $X_{1}$ and $q^{2}$ units of $X_{2}$. The variable cost function associated with this production function is therefore

$$
C(q, k)=\frac{c}{\gamma(k)} q+\frac{\delta}{2} q^{2}
$$

where $c$ denotes the unit cost of the variable factor input $X_{1}$ and $\frac{\delta}{2}$ denotes the unit cost of the variable factor input $X_{2}$. It can be shown that this cost function's long-run average cost curve observes the conventional U-shaped pattern.

Notice that the first term in the cost function comes from the variable input $X_{1}$ while the second term comes from the variable input $X_{2}$. The linear first term implies that capital investment affects the intercept of the marginal cost curve only, while the quadratic second term implies that the marginal cost is linearly increasing in output. For almost all our results, we need only the first term and hence only one variable input. An increasing marginal cost 
curve is needed, however, if we are to incorporate the special case of price-taking firms into our analysis.

Since capital takes time to be put in place, our model assumes that it must be committed and paid for at the beginning of the period. Labor and material, however, can be paid for when profits are realized, so the demand for these inputs is not constrained by the availability of financing. Providers of external finance for capital investment are usually at "arms length" and are not able to monitor the firm's managers easily. This leads to a moral hazard problem and capital rationing. In contrast, suppliers and workers can monitor the firm more closely, in which case it may be difficult for the firm to divert profits without paying suppliers and workers first. ${ }^{8}$ Notice that the claims of workers and suppliers (trade credit) are senior to debt used to finance investment; thus, firms can incur accounts payable and pay workers in arrears even when they cannot raise long-term financing from external markets.

\section{B Hedging and Production Costs}

For a given level of output $q$, the cost function (2) is convex in $k$, which implies that hedging reduces a firm's expected production costs. To determine the magnitude of the cost reduction achievable by hedging, we compare the cost functions of hedgers and nonhedgers.

The cost function of a firm that hedges is given by

$$
C^{h}(q, k)=\frac{\delta}{2} q^{2}+\frac{c}{\gamma(\bar{k})} q=\frac{\delta}{2} q^{2}+\alpha q
$$

where $\bar{k}=E(y)$ and

$$
\alpha \equiv \frac{c}{\gamma(\bar{k})}
$$


The cost function of a firm that does not hedge is given by

$$
\begin{aligned}
C^{u}(q, k) & =\frac{\delta}{2} q^{2}+\left(\frac{c}{\gamma(k)}-\frac{c}{\gamma(\bar{k})}\right) q+\frac{c}{\gamma(\bar{k})} q \\
C^{u}(q, w) & =\frac{\delta}{2} q^{2}+w q+\alpha q,
\end{aligned}
$$

where

$$
w \equiv \frac{c}{\gamma(k)}-\frac{c}{\gamma(\bar{k})}
$$

is a random variable that represents a shock to the fixed component of marginal costs. Since $\gamma(k)$ is a concave function, Jensen's Inequality implies

$$
E(w)=E\left(\frac{c}{\gamma(k)}-\frac{c}{\gamma(\bar{k})}\right)>0 .
$$

The fact that $E(w)$ is positive implies that hedging reduces a firm's expected production costs, where $E(w)$ represents the expected cost reduction per unit of output.

\section{Profit}

At time $T=1$, firms choose output to maximize profits, that is,

$$
\max _{q} \Pi(q, k)=P q-C(q, k),
$$

where $P$ denotes the unit price of output.

\section{Demand}

The industry demand curve is assumed to be linear,

$$
Q=\frac{a-P}{b},
$$

where $a>0$ and $b>0$ are constants, and $Q$ denotes industry output. 


\section{E Competition}

We assume that firms are Cournot competitors in the product market. Each firm observes the hedging choices of the other firms as well as the realization of the common cash flow shock before deciding on its own output. Equilibrium requires each firm's output choice to be a best response to the output choices of all other firms.

\section{The Profit Function of a Price-Taking Firm}

To develop the intuition, it is useful to first analyze the characteristics of the profit function of a firm that faces a constant, deterministic price $P$. We start at $\mathrm{T}=1$ with a single firm facing a given output price $P$. For a given $k$, profit maximization involves setting $q$ such that

$$
P=C_{q}=\delta q+\frac{c}{\gamma(k)} .
$$

The implied optimal output is a function of both $P$ and $k$ :

$$
q=\frac{1}{\delta}\left(P-\frac{c}{\gamma(k)}\right)
$$

A firm's profit function can be written, using equations (8) and (11), as

$$
\Pi(k, P)=P q-C(q, k)=\frac{1}{2 \delta}\left(P-\frac{c}{\gamma(k)}\right)^{2} .
$$

To ensure positive profits, production takes place only if $P-\frac{c}{\gamma(k)}>0$. The profit function is therefore given by

$$
\Pi(k, P)=\frac{1}{2 \delta} \max \left\{\left(P-\frac{c}{\gamma(k)}\right), 0\right\}^{2} .
$$

Note that the profit function is convex in $P$ (a standard result in microeconomics), which implies that for a fixed $k$, a firm benefits from volatility in the output price $P$. 
For sufficiently small values of $P$ the profit function is also convex with respect to $k$. To see this consider the second derivative of the profit function with respect to $k$ :

$$
\frac{\partial^{2} \Pi(k, P)}{\partial k^{2}}=\frac{2 c}{\delta k}\left(P-\frac{c}{\gamma(k)}\right) \frac{\gamma^{\prime}(k)}{\gamma(k)^{2}}\left[\frac{\gamma^{\prime \prime}(k) k}{\gamma^{\prime}(k)}-\frac{2 \gamma^{\prime}(k) k}{\gamma(k)}+\frac{c k}{P-\frac{c}{\gamma(k)}} \cdot \frac{\gamma^{\prime}(k)}{\gamma(k)^{2}}\right] .
$$

Only the third term within brackets, which represents the elasticity of output with respect to investment

$$
\frac{\partial q}{\partial k} \frac{k}{q}=\frac{c k}{P-\frac{c}{\gamma(k)}} \cdot \frac{\gamma^{\prime}(k)}{\gamma(k)^{2}}
$$

is positive and hence the source of convexity. Thus, the profit function is convex if the elasticity of output with respect to $k$ is sufficiently high. This is the case if $P$ is sufficiently small. ${ }^{9,10}$

The curvature of the profit function with respect to $k$ is significant because it determines a firm's incentive to hedge. On the one hand, the convexity of the cost function in $k$ (for a given $q$ ) generates concavity in the profit function in $k$, which makes hedging relatively attractive. However, notice that $q$ is chosen after the firm has invested $k$, and thus is itself a function of $k$. The fact that the output choice can be conditioned on the realizations of investment (or production cost), which we refer to as the production flexibility option, causes the profit function to be convex. This makes hedging relatively unattractive. ${ }^{11} \mathrm{~A}$ key observation from the above analysis is that the cost reduction effect, which gives firms an incentive to hedge, dominates if $P$ is large (making the profit function concave in $k$ ), while the production flexibility effect, which gives firms an incentive to increase volatility in production costs, dominates if $P$ is small (making the profit function convex in $k$ ).

Intuitively, as the product price increases and the firm produces more, the benefit of the lower expected production cost associated with hedging increase. ${ }^{12}$ Perhaps less obvious, the 
benefit of production flexibility enjoyed by an unhedged firm does not also increase in price. A firm producing at the random production cost earns a higher profit than a firm producing at the constant production cost when the cost realization is low (a gain) and a lower profit when the cost realization is high (a loss). Flexibility is valuable because its gain outweighs its loss, that is, it generates a net gain. If the marginal cost curve is linear, it can be shown that as the product price increases, both the gain and the loss increase by the same amount. As a result, the net gain is independent of the price. ${ }^{13}$

The tradeoff between the flexibility benefit of not hedging and the cost-reduction benefit of hedging can be seen by writing out the expected profits of a hedged and an unhedged firm. Using equations (4) and (12), the expected profit of a hedged firm is

$$
E \Pi^{h}(P)=\frac{1}{2 \delta}(P-\alpha)^{2} .
$$

Using equations (4), (6), and (12), the expected profit of an unhedged firm is

$$
\begin{aligned}
E \Pi^{u}(P) & =\frac{1}{2 \delta} E(P-\alpha-w)^{2} \\
& =\frac{1}{2 \delta}\left((P-\alpha)^{2}+E\left(w^{2}\right)-2(P-\alpha) E(w)\right) .
\end{aligned}
$$

The difference is given by

$$
E \Pi^{u}(P)-E \Pi^{h}(P)=\frac{1}{2 \delta}\left(E\left(w^{2}\right)-2(P-\alpha) E(w)\right) .
$$

The term $E\left(w^{2}\right)$ represents the benefit to nonhedgers of more volatile costs, which is independent of the price. The term $2(P-\alpha) E(w)$ represents the cost to nonhedgers of a higher expected marginal cost of production, which is increasing in the price since $E(w)>0$ from equation (7). A price-taking firm will therefore hedge (remain unhedged) if, ceteris paribus, the industry price is sufficiently high (low). 
In the next section, the price level is determined by demand and supply. In this case supply depends on the aggregate hedging decisions of all firms, as the unhedged firms' production decisions depend on the random realizations of their production costs. The hedging decisions of other firms therefore affect both the level and variability of the price. We show that this has a material effect on the hedging decision of an individual firm, and hence firms' hedging decisions are interdependent. ${ }^{14}$

\section{Subgame-Perfect Nash Equilibria (SPNE)}

Our model is a two-stage (dynamic) game with the following structure:

Stage 1: All firms simultaneously decide whether or not to hedge their cash flows, given the hedging strategies of all other firms.

Stage 2: After investing their cash flows and observing the investments made by other firms, all firms play a Cournot game in output.

The second stage is a standard Cournot game in which firms' cost functions are known. The equilibrium price and output depend on the number of firms that decide to hedge in the first stage and the realization of the cost shock $w$.

Let $\Pi^{u}\left(w, m^{u}\right)$ denote the profit of an unhedged firm in the second-stage game, and $\Pi^{h}\left(w, m^{u}\right)$ denote the profit of a hedged firm. Furthermore, let $E \Pi^{u}\left(w, m^{u}\right)$ and $E \Pi^{h}\left(w, m^{u}\right)$ denote the corresponding expected profits in the first stage. In a pure strategy subgameperfect equilibrium (SPNE), no firm has an incentive to change its hedging strategy given the hedging strategies of all other firms. Thus, there exists an equilibrium in which $m^{u^{*}}$ firms 
choose not to hedge if and only if the following conditions hold:

$$
\begin{aligned}
& E \Pi^{h}\left(w, m^{u^{*}}\right)>E \Pi^{u}\left(w, m^{u^{*}}+1\right) \\
& E \Pi^{u}\left(w, m^{u^{*}}\right)>E \Pi^{h}\left(w, m^{u^{*}}-1\right) .
\end{aligned}
$$

\section{A The Second Stage}

Consider the output decision of an unhedged firm after the cost shock $w$ has been realized.

Using equations (5) and (8), we obtain the profit function of an unhedged firm:

$$
\Pi^{u}\left(q_{i} ; w, m^{u}\right)=P\left(w, m^{u}\right) q_{i}-\frac{\delta}{2} q_{i}^{2}-w q_{i}-\alpha q_{i} .
$$

The first-order condition of profit maximization is

$$
\frac{\partial \Pi^{u}}{\partial q_{i}}=P\left(w, m^{u}\right)+q_{i} P_{Q} \frac{\partial Q}{\partial q_{i}}-\delta q_{i}-w-\alpha=0 .
$$

Note that the equilibrium price is not only a function of $w$ and $m^{u}$, but also of aggregate output $Q=\sum_{j=1}^{n} q_{j}$. In a Cournot-Nash equilibrium, each firm's output decision must maximize profit, given the output decisions of all other firms. Thus, $\frac{\partial Q}{\partial q_{i}}=1$. Substituting in the slope of the demand curve, $P_{Q}=-b$, the profit-maximizing output of an unhedged firm is given by

$$
q^{u}=\frac{P\left(w, m^{u}\right)-w-\alpha}{\delta+b} .
$$

Analogous steps yield the profit-maximizing output of a hedged firm:

$$
q^{h}=\frac{P\left(w, m^{u}\right)-\alpha}{\delta+b} .
$$

The equilibrium in the second stage is defined by equations (21), (22), and the marketclearing condition

$$
q^{u} m^{u}+q^{h} m^{h}=Q=\frac{a-P\left(w, m^{u}\right)}{b} .
$$


Solving for the equilibrium price and output, we obtain

$$
\begin{aligned}
P\left(w, m^{u}\right)-\alpha & =\frac{(a-\alpha)(\delta+b)}{n b+\delta+b}+\frac{b m^{u}}{n b+\delta+b} w \\
Q\left(w, m^{u}\right) & =\frac{(a-\alpha) n-w m^{u}}{n b+\delta+b} .
\end{aligned}
$$

Note how the expected equilibrium price (and quantity) depend on the aggregate hedging decisions. Since $E(w)$ is positive, as more firms decide not to hedge ( $m^{u}$ increases), the expected equilibrium price increases and the expected output falls. Aggregate hedging decisions also affect the volatility of the equilibrium price: The equilibrium price becomes more volatile as more firms remain unhedged. However, since in equilibrium the number of firms that hedge is itself determined as a function of the other parameters in equations (24) and (25), we refrain from deriving any comparative static implications until later in our analysis.

Substituting the optimal output from (21) into equation (19) yields the profit function of an unhedged firm:

$$
\Pi^{u}\left(w, m^{u}\right)=\frac{\delta+2 b}{2(\delta+b)^{2}}\left(P\left(w, m^{u}\right)-w-\alpha\right)^{2} .
$$

Analogous substitutions yield the profit function of a hedged firm:

$$
\Pi^{h}\left(w, m^{u}\right)=\frac{\delta+2 b}{2(\delta+b)^{2}}\left(P\left(w, m^{u}\right)-\alpha\right)^{2} .
$$

Note that for a hedged firm, the volatility of profit is that of $P\left(w, m^{u}\right)$ only, while for an unhedged firm, the relevant volatility is that of $P\left(w, m^{u}\right)-w$. Since $P\left(w, m^{u}\right)$ and $w$ are positively correlated, as indicated by equation (24), they partially offset each other (a natural hedge). This fact plays an important role in a firm's decision to hedge, as we show below. 


\section{$B$ The First Stage}

To decide whether or not to hedge in the first stage, a firm compares the expected profit of hedging with the expected profit of not hedging, given the hedging choices of all other firms. To gain some intuition about the factors affecting the choice of the firm's hedging decision, it is useful to compare, for any given choice of hedging strategies of all firms, the expected profit of a firm that is currently hedged and one that is not. From equations (26) and (27), we have

$$
E \Pi^{u}\left(w, m^{u}\right)-E \Pi^{h}\left(w, m^{u}\right)=\frac{\delta+2 b}{2(\delta+b)^{2}}\left(E\left(w^{2}\right)-2 E\left\{\left(P\left(w, m^{u}\right)-\alpha\right) w\right\}\right) .
$$

Equation (28) is similar to equation (16) except that here, the price is endogenous and affected by the hedging choices of all firms.

After multiplying both sides of equation (24) by $w$, taking expectations, and rearranging terms slightly, we get the following:

LEMMA 1: Consider an industry with $n$ firms, of which $m^{u}$ firms do not hedge. Then the difference between the expected profits from not hedging and hedging is given by

$$
\begin{aligned}
& E \Pi^{u}\left(w, m^{u}\right)-E \Pi^{h}\left(w, m^{u}\right) \\
= & \frac{(\delta+2 b)}{2(\delta+b)^{2}}\left[\left(1-\frac{2 b m^{u}}{n b+\delta+b}\right) E\left(w^{2}\right)-\frac{2(a-\alpha)(\delta+b)}{n b+\delta+b} E(w)\right] .
\end{aligned}
$$

Proof: See the Appendix.

Lemma 1 shows that the difference in the payoff between an unhedged and a hedged firm is determined by two terms, one associated with $E(w)$ and the other associated with $E\left(w^{2}\right)$. Recall that $E(w)$ is the expected reduction in the unit production costs that a firm can achieve by hedging. Therefore, the second term within square brackets represents the cost of 
remaining unhedged that arises from the higher expected cost of production. Since this term is always negative and does not depend on other firms' hedging decisions, it always provides firms an incentive to hedge. Moreover, it is larger in magnitude the larger the intercept term in equation (24), that is, the larger the exogenous component of the price. As a result, this term is increasing in the intercept of the demand curve and decreasing in the number of firms in the industry.

Consider now the first term within square brackets in (29). This term is proportional to $E\left(w^{2}\right)$, which is related to the volatility of unit production costs caused by the volatility in cash flows, and represents the real option benefit of volatile cash flows. In contrast to the case of a price-taking firm (see equation (16)), the real option benefit is now a function of the hedging decisions of other firms. Thus, the more the number of firms that remain unhedged, the greater is the incentive for an individual firm to hedge and vice versa. ${ }^{15}$ This negative dependence creates the possibility of an interior equilibrium in which some firms hedge and others do not.

To understand the interrelation between firms' hedging choices, consider how hedging allows firms to shift cash flows across states of nature. The production flexibility implies that a firm benefits most if it shifts its cash flows to those states in which other firms have relatively low cash flows and vice versa. For example, in a state in which aggregate cash flows are relatively low, aggregate output will be low and the equilibrium price will be high if most firms are unhedged. As a result, profit opportunities will be high. A firm can benefit from this situation by hedging, which will give it a relatively high cash flow in this particular state. Conversely, if most firms are hedging, then by remaining unhedged a firm benefits by 
increasing investment when cash flows are high and thereby producing more than its hedged rivals. The incentive to take hedging positions that are opposite those of its rivals derives precisely from these effects.

\section{B.1 The Case of a Flat Demand Curve}

It is instructive to consider an industry in which all firms are price-takers. Suppose that the industry demand curve is flat $(b=0)$, so that the price is fixed. Here, we again consider the case of the price-taking firm facing a constant price as in Section II, except that we now look at the industry equilibrium. In this case the equilibrium price is a constant $(P(w)=a)$, and Lemma 1 reduces to

$$
E \Pi^{u}\left(w, m^{u}\right)-E \Pi^{h}\left(w, m^{u}\right)=\frac{1}{2 \delta}\left[E\left(w^{2}\right)-2(a-\alpha) E(w)\right] .
$$

This equation is very similar to equation (16) in Section II. If $a$ is sufficiently large, then all firms hedge. Intuitively, a sufficiently high output price implies that firms operate in the concave region of their profit functions (see equation (14)). Therefore, all firms hedge. If $a$ is sufficiently small, then all firms remain unhedged. Equation (30) shows that an interior solution does not exist. The reason is that the equilibrium price is no longer a function of the number of firms that hedge. Therefore, the incentive to hedge or not hedge is the same for all firms, so that in equilibrium either all firms hedge or all firms remain unhedged, depending on whether the cost reduction effect or the production flexibility effect dominates. This example demonstrates the importance of a downward-sloping demand function for the existence of an interior equilibrium. 


\section{Analysis of the Equilibrium}

The following proposition gives necessary and sufficient conditions for the existence of an equilibrium.

PROPOSITION 2: Let $\bar{m}^{u}$ be the real number (if it exists) in the interval $[0, n]$ for which the right-hand side of (29) is zero, $m_{1}^{u}$ be the largest integer value of $m^{u}$ for which the right-hand side of (29) is positive, and $m_{2}^{u}=m_{1}^{u}+1$ be the smallest integer value for which it is negative.

1. If $\bar{m}^{u}$ is an integer value, ${ }^{16}$ then the equilibrium number of firms that remain unhedged is given by $\bar{m}^{u}$.

2. If $\bar{m}^{u}$ is not an integer, two cases arise:

(a) If $E \Pi^{u}\left(w, m_{2}^{u}\right)<E \Pi^{h}\left(w, m_{1}^{u}\right)$, then the equilibrium number of firms that remain unhedged is $m_{1}^{u}$.

(b) If $E \Pi^{u}\left(w, m_{2}^{u}\right)>E \Pi^{h}\left(w, m_{1}^{u}\right)$, then the equilibrium number of firms that remain unhedged is $m_{2}^{u}$.

Proof: See the Appendix.

Proposition 2 implies that the proportion of firms that do not hedge in equilibrium can be obtained approximately by setting equation (29) equal to zero.

PROPOSITION 3: The proportion of firms that remain unhedged in equilibrium, $\frac{m^{u}}{n}$, lies within the bounds

$$
\frac{1}{2}+\left(\frac{1}{n}+\frac{\delta}{n b}\right)\left[\frac{1}{2}-(a-\alpha) \frac{E(w)}{E\left(w^{2}\right)}\right] \pm \frac{1}{n}
$$


provided the bounds are within the unit interval. If the lower of the two bounds exceeds unity, all firms remain unhedged. If the higher of the two bounds is negative, all firms hedge.

Proof: Immediate from Lemma 1 and Proposition 2.

Let us define

$$
\theta \equiv \frac{1}{2}-(a-\alpha) \frac{E(w)}{E\left(w^{2}\right)}
$$

If $\theta=0$, then approximately one-half of the firms hedge and one-half of the firms do not, for large $n$. This is the point of maximum heterogeneity, that is, maximum diversity in hedging strategies. ${ }^{17}$ If $\theta<0$, then the fraction of firms that hedge is greater than one-half $\left(\frac{m^{u}}{n}<\frac{1}{2}\right)$. If $\theta>0$, then the fraction of firms that hedge is less than one-half $\left(\frac{m^{u}}{n}>\frac{1}{2}\right)$. Whether the equilibrium entails the majority of firms hedging or not hedging depends on the market size, as measured by the difference between the demand intercept $a$ and the intercept of the marginal cost curve $\alpha \cdot{ }^{18}$ If the market is sufficiently large, $\theta$ is negative and the majority of firms will hedge. If the market is small, a majority of firms will not hedge.

These results - stated more formally below - are intuitive. As we noted earlier, a larger market size increases the magnitude of the cost-reducing effect of hedging, leaving an unhedged firm's flexibility benefit unaffected. Thus, for sufficiently large market size, a majority of the firms hedge. Comparing the definition of $\theta$ with the expression within square brackets in equation (30) (which corresponds to Lemma 1 for the case of a flat demand curve) reveals an interesting feature of the equilibrium. If equation (30) is negative (the cost effect dominates the production flexibility effect), then $\theta$ is negative; if equation (30) is positive (the production flexibility dominates the cost effect effect), then $\theta$ is positive. Thus, irrespective of the number of firms in the industry and the slopes of the demand and marginal cost curves, 
under the same set of parameters for which all firms in a price-taking industry would hedge (or remain unhedged), a majority of firms in any other industry would do the same. It is also clear from this comparison that $\theta$ measures the relative dominance of the production flexibility versus the cost reduction effects if the aggregate hedging strategies have no impact on the equilibrium price.

\section{Comparative Statics}

We now consider how the proportion of firms that hedge, and hence the proportion that do not hedge depends on industry characteristics such as the number of firms in the industry (extent of competition), the convexity of the cost function, the slope of the demand function, and the size of the market.

PROPOSITION 4: Consider an industry with a fixed number of firms. If $\theta$ is negative (positive), then the proportion of firms that choose not to hedge:

1. Is less than $\frac{1}{2}+\frac{1}{n}$ (greater than $\frac{1}{2}-\frac{1}{n}$ ).

2. Decreases (increases) as

(a) the industry demand curve becomes flatter (b decreases, with intercept unchanged $)^{19}$

(b) production flexibility decreases ( $\delta$, the convexity of the cost function increases)

(c) the number of firms in the industry decreases (n decreases).

Proof: Immediate from equation (31). ${ }^{20}$

We discuss part 1 of Proposition 4 above. The results in part 2 of Proposition 4 indicate 
how the proportion of firms that do not hedge (or hedge) changes in equilibrium as industry parameters change.

A useful way to understand part 2 of Proposition 4 is to realize that all parameter changes considered here (a flatter industry demand curve, a steeper marginal cost curve, and fewer firms in the industry) cause the proportion of firms that hedge to move away from the ratio of one-half, the point of maximum heterogeneity in hedging strategies, irrespective of whether $\theta$ is positive or negative. If $\theta>0$, the proportion of firms that do not hedge moves away from one-half and towards one, while if $\theta<0$, the proportion of firms that do not hedge moves away from one-half and towards zero, as the industry demand curve flattens, the marginal cost curve steepens, or the number of firms in the industry decreases. Thus, the parameter changes considered here all lead to less heterogeneity in hedging strategies. As we see above, whether the equilibrium entails the majority of firms hedging or not hedging depends on the sign of $\theta$, which captures the relative cost-benefit of hedging versus not hedging for a pricetaking industry $(b=0)$ in which firms' hedging decisions are not interdependent. However, under the parameter changes indicated in Proposition 4, more firms will join the majority and the equilibrium will become less heterogenous.

To understand why the parameter changes have this implication, consider first the effect of a flatter industry demand curve (lower $b$ ) or steeper marginal cost curve (higher $\delta$ ). Notice from equation (24) that each of these changes has two "direct" effects: (a) The average industry price is higher, and (b) the volatility of the price is lower. ${ }^{21}$ A flatter (more elastic) industry demand curve, holding the intercept of the demand curve $a$ unchanged, implies that the output price is less volatile. A flatter demand curve (with intercept unchanged) also 
implies that the average industry price is higher, ceteris paribus. The effect of a steeper marginal cost curve is similar: A steeper marginal cost curve lowers the price volatility associated with random shocks to its intercept and it lowers production, which raises prices. A lower price volatility increases the incentive for an individual firm to remain unhedged in order to maximize the value of its production flexibility. However, a higher industry price increases the incentive to hedge in order to benefit from the cost reduction effect. Thus, there are two opposing effects of a decrease in the slope of the demand curve or an increase in the slope of the marginal cost curve: One increases the incentive to remain unhedged, while the other decreases that incentive. Which of these two effects dominates depends on the size of the market, $a-\alpha$. If the size of the market is sufficiently small $(\theta>0)$, then the benefit from the cost-reducing effect is lower and remaining unhedged is more attractive. What our results show is that, in this situation, the lower sensitivity of the industry price to unhedged firms' cost shocks will have a more dominant effect on the incentive to remain unhedged than the offsetting effect of a higher average industry price. The latter effect is less important because the average industry price is still relatively low if the market is small, and therefore the loss associated with the higher expected marginal cost of production from remaining unhedged is not very high. Exactly the opposite holds if the market is relatively large $(\theta<0)$, so that a flatter demand curve encourages more hedging.

This leaves the case of a smaller number of firms in the industry (lower $n$ ). Unlike the other two cases, a smaller number of firms in the industry will raise both the price and the volatility of the price. This unambiguously increases the incentive to hedge, that is, $m^{u}$ decreases. However, whether $\frac{m^{u}}{n}$ increases or decreases depends on the the proportion of 
firms that are already unhedged. When this proportion exceeds one-half $(\theta>0)$, remaining unhedged is still relatively attractive, so that $m^{u}$ decreases less than proportionately, i.e. $\frac{m^{u}}{n}$ increases. On the other hand, if the proportion is less than $\frac{1}{2}(\theta<0)$, conditions are favorable for hedging, so the higher volatility and price level cause a bigger switch from the rank of nonhedgers to hedgers. Thus, $\frac{m^{u}}{n}$ decreases.

In contrast to the results of Proposition 4, the following results do not depend on whether $\theta$ is positive or negative.

PROPOSITION 5: The bounds for the proportion of firms that choose not to hedge in expression (31):

1. Decrease as $\frac{E w}{E w^{2}}$ increases.

2. Decrease as a, the intercept of the demand curve, increases.

Proof: Immediate from the expression in (31).

The intuition for these results is as follows. An increase in $\frac{E w}{E w^{2}}$, or an increase in the average market price (due to a higher demand intercept $a$ ), makes it more costly for a firm not to hedge, as discussed above. Hence, the proportion of firms that choose not to hedge decreases.

Equation (24) suggests that the sensitivity of the industry price to cost shocks, $\frac{d P}{d w}=$ $\frac{b m^{u}}{n b+\delta+b}=\frac{n b\left(m^{u} / n\right)}{n b+\delta+b}$, depends on the proportion of firms that remain unhedged as well as the industry parameters $n, b$, and $\delta$. Not surprisingly, a higher proportion of firms that remain unhedged causes the price sensitivity to be higher, ceteris paribus. Nain (2005) finds that industry prices are less responsive to foreign exchange rates when currency hedging is more 
widespread. However, our analysis shows that the proportion of firms that hedge is itself a function of industry parameters. Thus, a change in the industry parameters will have a direct effect on the sensitivity, as well as an indirect effect by affecting the proportion of firms that hedge. Interestingly, although the direct and indirect effects do not always work in the same direction (the direction of the indirect effect depends on whether $\theta$ is greater or less than zero), the net effect is unambiguous:

PROPOSITION 6: The sensitivity of the equilibrium industry price to the cost shock $\left(\frac{d P}{d w}\right)$ is increasing in the number of firms ( $n$ ) and the slope of the demand curve (b), but decreasing in the slope of the marginal cost curve $(\delta)$.

Proof: Please see the Appendix.

In the next section, we turn to some extensions of our model.

\section{Model Extensions}

In this section, we consider three extensions of our model. We first analyze the case of stochastic demand in order to clarify the relationship between our framework and that of FSS (1993). Next, we investigate how the equilibrium changes if some firms are financially unconstrained. Finally, we check whether our equilibrium continues to exist if firms can choose from a continuum of hedging strategies (partial hedging). ${ }^{22}$

\section{A Stochastic Demand}

FSS (1993) show that given a profit function that is concave in investment, a financially constrained firm prefers to hedge its cash flows as long as the covariance between cash flows 
(profits) and investment opportunities is not too high. In their framework, the concavity of the profit function gives the firm a natural incentive to hedge. On the other hand, financially constrained firms prefer to increase their cash flows in those states of nature in which their investment opportunities are high. Thus, if the covariance between cash flows and investment opportunities is sufficiently high, then even with concave profit functions financially constrained firms are better off remaining unhedged.

FSS (1993) do not explicitly model the production decisions of firms, but choose instead to work in terms of a "reduced-form" profit function that is concave in investment. However, as we show below, the FSS (1993) intuition can be accommodated in our framework by assuming a positive covariance between the current demand intercept and (last period's) cash flows. This covariance gives firms an additional incentive to remain unhedged, and as we show, an increase in this covariance leads more firms to choose to remain unhedged in equilibrium. The intuition is that by remaining unhedged, firms enjoy higher (lower) cash flows and investment in states in which the industry price is high (low). As a result, they can produce more (less) when costs are low (high) and increase their expected profits.

To see this more formally, let the industry demand curve be denoted by

$$
P=(a+\epsilon)-b Q,
$$

where $\epsilon$ is a random variable with $E(\epsilon)=0$ and $\operatorname{Cov}(\epsilon, y)>0$. One way to think of this is that cash flows reflect profits from the previous period's production, and the previous period's profits are high if the demand realization was high. If shocks to the demand curve are serially correlated, then with financial constraints, there is a positive covariance between 
investment and the demand intercept this period. Thus, we have

$$
\operatorname{Cov}(\epsilon, y)>0 \Longrightarrow \operatorname{Cov}(\epsilon, w)<0 \text {. }
$$

Following steps similar to those in the proof of Lemma 1 and Proposition 3, one can show that the bounds on $\frac{m^{u}}{n}$ are given by

$$
\frac{1}{2}+\left(\frac{1}{n}+\frac{\delta}{n b}\right)\left[\frac{1}{2}-(a-\alpha) \frac{E(w)}{E\left(w^{2}\right)}\right]-\left(\frac{1}{n}+\frac{\delta}{n b}\right) \frac{\operatorname{Cov}(\epsilon, w)}{E\left(w^{2}\right)} \pm \frac{1}{n} .
$$

Note that $\operatorname{Cov}(\epsilon, w)<0$. Thus, ceteris paribus, the proportion of firms that remain unhedged when the demand intercept and cash flows are positively correlated is higher than when they are uncorrelated. It is also clear from a comparison of equations (31) and (34) that all our previous results go through if we redefine $\theta$ as

$$
\theta=\frac{1}{2}-(a-\alpha) \frac{E(w)}{E\left(w^{2}\right)}-\frac{\operatorname{Cov}(\epsilon, w)}{E\left(w^{2}\right)} .
$$

The model outlined in earlier sections stresses that production flexibility is beneficial in that a firm producing at a random production cost can choose output after observing the cost realization, which allows the firm to produce less when the cost is high, but more when the cost is low. Here, the ability to choose production after the realization of production costs, together with the negative correlation between production costs and the demand intercept, makes it even more attractive to remain unhedged. However, as more firms remain unhedged, the incentive for an individual firm to remain unhedged is somewhat dampened. This is because firms that remain unhedged invest more, and thus produce more, when demand is high. This increased production lowers prices, somewhat offsetting the effect of higher demand, and as a result, lowers the incentive to remain unhedged. In equilibrium, firms are 
indifferent between hedging and not hedging, as is the case in our earlier model, although a higher proportion of firms are required not to hedge to bring about this indifference.

Notice that the addition of stochastic demand has surprisingly little effect on our comparative static results. To see why this is the case, recall that our earlier results in Propositions 4 through 6 follow from the fact that while the benefit of remaining unhedged due to production flexibility is independent of the demand intercept, the cost of remaining unhedged is increasing in the intercept of the demand curve. In the extended model of this section the covariance between the shock to the demand intercept and cash flows that gives rise to an additional benefit from remaining unhedged is also independent of the expected value of the demand intercept, while the cost from not hedging is increasing in the latter. As a result, the effect of parameter changes on the relative cost and benefit of remaining unhedged is still determined by the position of the demand intercept, and our comparative static results are qualitatively unchanged.

\section{$B \quad$ Unconstrained Firms}

Our analysis above assumes that all firms are financially constrained and thus they always invest less than their unconstrained optimum. We now consider the possibility that $m^{u c}$ firms in the industry are unconstrained and thus they invest at the first-best levels. In general, the first-best investment levels of these firms depend on the hedging and investment decisions of the other firms in the industry, and are determined as part of a Nash equilibrium.

It is clear, however, that in equilibrium, the unconstrained firms will invest more in states of nature in which the constrained firms invest relatively less, that is, their cash flows are 
lower. This is because the industry price is higher if the investment and cash flows are lower, providing the unconstrained firms greater incentive to invest more. Hence, the presence of unconstrained firms reduces the sensitivity of the industry price to the cash flow shock, which in turn provides the constrained firms a higher incentive to remain unhedged. As a result, in equilibrium a higher proportion of firms will remain unhedged when some of the firms are unconstrained compared to a situation in which all firms are constrained. In the Appendix, we show that if a given number of firms in the industry become unconstrained, then the number of firms that choose to remain unhedged will not only increase as a proportion of the constrained firms, but also as a proportion of all firms in the industry.

\section{Continuous Hedging Strategies}

Up to this point we have assumed that firms follow discrete hedging strategies, that is, firms either completely hedge their cash flows or they do not hedge at all. In this section, we briefly describe the consequences of relaxing this particular assumption.

Assume that firms can choose from a continuum of hedging strategies and let $h \in[0,1]$ represent a firm's hedge ratio. Then the firm's cash flow at time $\mathrm{T}=1$ is given by

$$
y_{h}=(1-h) y+h \bar{y} .
$$

In two-stage games with continuous strategy spaces in the first stage, symmetric equilibria typically exist, although asymmetric equilibria may also exist. Since our entire analysis above is based on the latter type of equilibria (in which some firms hedge completely, and the rest do not hedge at all), the question of whether or not such equilibria are robust to the introduction of continuous hedging strategies needs to be considered. 
In unreported work, ${ }^{23}$ we examine a Nash equilibrium with two firms that can choose from a continuum of hedging strategies. The equilibrium can be characterized as the intersection of the reaction function of each firm. We solve the second-stage game and then derive the reaction function of each firm, that is, for any hedging strategy $h_{j}$ of firm $j$, where $h_{j} \in[0,1]$, we derive the optimal response $h_{i} \in[0,1]$ of firm $i$. Since the firms are ex-ante symmetric, these reaction functions are also symmetric. Therefore, if the reaction functions are continuous, a symmetric equilibrium in which the hedging strategy of each firm is in the interior of the unit interval must exist.

We find that for a range of parameter values, the reaction functions are discontinuous, so that an interior equilibrium does not exist. The only equilibria are corner solutions. The discontinuity arises because the profit function of a given firm is typically convex in its own hedging strategy, holding that of the other firm fixed; at the point of discontinuity, the firm is indifferent between choosing $h=0$ or $h=1$. The corner solutions involve both firms hedging $\left(h_{i}=1, i=1,2\right)$, both firms not hedging $\left(h_{i}=0, i=1,2\right)$, or one firm hedging and the other remaining unhedged $\left(h_{i}=1, h_{j}=0, i \neq j, i=1,2\right)$.

Next, we extend the example to a larger number of firms $(n=20)$. The parameters are chosen such that, if $h$ of every firm is restricted to either zero or one, the equilibrium of the previous section implies that exactly 10 firms hedge, and the other 10 remain unhedged. We show that this particular equilibrium remains when $h$ is allowed to take any value in the unit interval and no symmetric equilibrium exists. Thus, all our earlier results go through when a continuum of hedging strategies is allowed. 


\section{Empirical Implications and Relationship to Existing Empirical Evidence}

Our model is motivated by the observed heterogeneity of hedging practices that is typical of many industries. Existing empirical models of hedging behavior explain only a relatively small percentage of the within-industry variation in hedging practices. ${ }^{24}$ Our equilibrium analysis indicates that identical firms can make very different hedging choices, which may explain the low correlation between hedging behavior and firm characteristics.

Another dimension of hedging behavior that has been noted - but not extensively studied - is that of "between-industry" variation in the proportion of firms that hedge. Here, our model produces potentially testable implications, provided meaningful empirical constructs of industry characteristics can be found. For example, Proposition 4 suggests that there will be more heterogeneity in firms' hedging strategies (i.e., the proportion of firms that hedge will be closer to one-half) if, ceteris paribus,

- An industry is more competitive (more firms in an industry).

- Demand is less elastic (steeper demand curve).

- Production technologies exhibit more flexibility (marginal cost curve is less steep).

In addition, Proposition 5 and Section B suggest that the proportion of firms that hedge in a particular industry is higher if

- The proportion of financially constrained firms is higher. ${ }^{25}$

- The size of the market is larger $(a-\alpha$ is larger $)$. 
- The factor whose marginal productivity is affected by capital investment $\left(X_{1}\right)$ contributes less to the variable cost of production. ${ }^{26}$

In addition, our model has implications about how output prices respond to shocks under different conditions. Specifically, the model implies that the sensitivity of the industry price to common shocks that affect cash flows, and hence the production costs of firms in an industry, will be higher if: ${ }^{27}$

- The industry is more competitive (more firms in an industry).

- Demand is less elastic (steeper demand curve).

- Production technologies exhibit more flexibility (less convexity in production cost).

These implications are interesting because at first glance it might appear that the sensitivity of industry price to cost shocks will be higher if the proportion of firms that are unhedged is higher. However, the latter variable is itself endogenous and depends on industry parameters. The parameter configurations listed above, which lead to a higher sensitivity, are precisely the ones for which there is more heterogeneity in hedging strategies, that is, the proportion of firms that hedge is closer to one-half (see Proposition 4). Thus, the observed relationship between the price sensitivity and the proportion of firms that hedge is an inverted U-shape, with the sensitivity initially increasing, and then decreasing, in the proportion of firms that remain unhedged..$^{28}$

To date there is only a limited amount of empirical evidence on how industry characteristics affect the hedging behavior of firms. Allayannis and Weston (1999) find that firms 
operating in industries with lower price-cost margins are more likely to use foreign currency derivatives, as shown in Figure 1. It is noteworthy that in most of the industries that Allayannis and Weston consider, the percentage of firms that use derivatives is less than one-half (see the upper panel of Figure 1), which is consistent with these industries having $\theta>0$ (the production flexibility effect dominates the cost reduction effect). In this case our model predicts a positive relation between the number of firms and the proportion of firms that hedge. Since in our model a higher number of firms in an industry implies, ceteris paribus, a lower price-cost margin, our result is consistent with Allayannis and Weston (1999).

Figure 1 about here

Our results are also consistent with the findings of Géczy, Minton, and Schrand (1997) who find that firms with better growth opportunities and tighter financial constraints are more likely to use currency derivatives. Géczy, Minton, and Schrand (1997) present data on the number of firms in different industries using currency derivatives, which we reproduce in the lower panel of Figure 1. The data reveal an inverted U-shaped relationship between the number of firms in each industry and the proportion of firms that use derivatives. This observation is consistent with Proposition 4. It is easy to check from equation (31) that when the fraction of firms that hedge is less than one-half, $\theta$ must exceed zero. Thus, in this case there must be a positive relationship between the number of firms in the industry and the fraction of firms that hedge. On the other hand, if the fraction of firms that hedge exceeds one-half, $\theta$ is less than zero, and the relationship between the number of firms in the industry and the fraction of firms that hedge will be negative. 
In trying to relate the results in the above studies to the implications of our model the following caveat should be noted. Most of these studies use firms' derivatives choices as a proxy for hedging choices. However, as Petersen and Thiagarajan (2000) point out, firms can hedge cash flows in many different ways, including other financial and operating strategies. ${ }^{29}$ For example, financially constrained firms may build up cash balances as a buffer against future cash shortfalls when they have good investment opportunities, which might be considered a form of "hedging." ${ }^{30}$ While our model makes no particular assumptions about how firms hedge, the possibility that firms can hedge in many different ways poses some challenges for empirical research interested in examining the cross-industry determinants of hedging behavior.

\section{Conclusion}

The existing literature explores how financial constraints impact the incentive for firms to hedge. Our analysis contributes to this literature by showing that under fairly standard assumptions the profit function of a financially constrained firm may be convex in the level of investment, which implies that these firms may have an incentive to speculate rather than hedge. A further contribution of our model is that it shows that a firm's incentive to hedge depends partially on the hedging choices of other firms in the same industry. Specifically, the incentives of an individual firm to hedge decreases as more firms hedge, and increases as more firms choose not to hedge. In the spirit of Maksimovic and Zechner (1991) and Shleifer and Vishny (1992), we show that the proportion of firms that hedge is determined within the

equilibrium. Further, in equilibrium, individual firms are indifferent between hedging and 
not hedging.

Our analysis helps us understand why we observe extensive diversity in risk management strategies even within the same industry. Tufano (1996) suggests that this diversity is due to differences in managers' compensation packages, which in turn provide different incentives to hedge. However, this explanation begs the question of why shareholders would give different managers different incentives to hedge if hedging is deemed beneficial. Our analysis suggests that the diversity in hedging strategies can be a feature of the equilibrium, even if all firms are identical ex ante.

While there is strong evidence of heterogeneity in hedging choices in specific industries such as gold mining and oil and gas, we are not aware of a more general study of heterogeneity in hedging choices across all industry sectors. Our analysis predicts that in industries with more competition, more inelastic demand, and less convexity in production costs, we should observe more heterogeneity in hedging choices. In addition, a larger fraction of firms will hedge in industries that are subject to tighter financial constraints and industries with larger markets. 


\section{References}

Aabo, Tom, and Betty J. Simkins, 2005, Interaction between real options and financial hedging: Fact or fiction in managerial decision-making, Review of Financial Economics 14, 353-369.

Acharya, Viral V., Heitor Almeida, and Murillo Campello, 2006, Is cash negative debt? A hedging perspective on corporate financial policies, Working paper, SSRN.

Adam, Tim Rene, Sudipto Dasgupta, and Sheridan Titman, 2006, Financial constraints, competition, and hedging in industry equilibrium, Working paper, SSRN.

Almeida, Heitor, Murillo Campello, and Michael S. Weisbach, 2004, The cash flow sensitivity of cash, Journal of Finance 59, 1777-1804.

Allayannis, George, and Eli Ofek, 2001, Exchange rate exposure, hedging, and the use of foreign currency derivatives, Journal of International Money and Finance 20, 273-296.

Allayannis, George, and James P. Weston, 1999, The use of currency derivatives and industry structure, in Greg Brown and Don Chew, eds.: Corporate Risk: Strategies and Management (Risk Books).

Allayannis, George, and James P. Weston, 2001, The use of foreign currency derivatives and firm market malue, Review of Financial Studies 14, 243-276.

De Meza, David, 1986, Safety in conformity but profits in deviance, Canadian Journal of Economics 19, 261-269. 
DeMarzo, Peter M., and Darrell Duffie, 1995, Corporate incentives for hedging and hedge accounting, Review of Financial Studies 8, 743-771.

Fenn, George W., Mitch Post, and Steven A. Sharpe, 1996, Debt maturity and the use of interest rate derivatives by nonfinancial firms, Board of Governors of the Federal Reserve System, Finance and Economics Discussion Series.

Froot, Kenneth, David S. Scharfstein, and Jeremy C. Stein, 1993, Risk management: Coordinating corporate investment and financing policies, Journal of Finance 48, 16291658.

Géczy, Christopher, Bernadette A. Minton, and Catherine Schrand, 1997, Why firms use currency derivatives, Journal of Finance 52, 1323-1354.

Haushalter, G. David, 2000, Financing policy, basis risk, and corporate hedging: Evidence from oil and gas producers, Journal of Finance 55, 107-152.

Kaplan, Steven N., and Luigi Zingales, 1997, Do financing constraints explain why investment is correlated with cash flow? Quarterly Journal of Economics 112, 169-216.

Maksimovic, Vojislav, and Josef Zechner, 1991, Debt, agency costs, and industry equilibrium, Journal of Finance 46, 1619-1643.

Mello, Antonio S., and Martin E. Ruckes, 2005, Financial hedging and product market rivalry, Working paper, University of Wisconsin-Madison.

Mello, Antonio S., and John Parsons, 2000, Hedging and liquidity, Review of Financial Studies 13, 127-153. 
Mian, Shehzad L., 1996, Evidence on corporate hedging policy, Journal of Financial and Quantitative Analysis 31, 419-439.

Nain, Amrita, 2005, The strategic motives for corporate risk management, Working paper, McGill University.

Nance, Deana R., Clifford W. Smith, and Charles W. Smithson, 1993, On the determinants of corporate hedging, Journal of Finance 48, 267-284.

Petersen, Mitchell, and S. Ramu Thiagarajan, 2000, Risk measurement and hedging: With and without derivatives, Financial Management 29, 5-30.

Rajagopal, Shivaram, and Morton Pincus, 2000, The interaction of accounting policy choice and hedging: Evidence from oil and gas firms, Working paper, University of Washington.

Shleifer, Andrei, and Robert W. Vishny, 1992, Liquidation values and debt capacity: A market equilibrium approach, Journal of Finance 47, 1343-1366.

Simkins, Betty J., and Daniel A. Rogers, 2006, Asymmetric Information and Credit Quality: Evidence from Synthetic Fixed-rate Financing, Journal of Futures Markets $26,595-625$.

Smith, Clifford, and René M. Stulz, 1985, The determinants of firms' hedging policies, Journal of Financial and Quantitative Analysis 28, 391-405.

Stulz, René M., 1990, Managerial discretion and optimal financing policies, Journal of Financial Economics 26, 3-27. 
Stulz, René M., 1984, Optimal hedging policies, Journal of Financial and Quantitative Analysis 19, 127-140.

Tufano, Peter, 1996, Who manages risk? An empirical examination of risk management practices in the gold mining industry, Journal of Finance 51, 1097-1137. 


\section{Footnotes}

${ }^{1}$ These include convex tax schedules, bankruptcy costs, information asymmetries, agency costs, and the presence of undiversified stakeholders. See Stulz (1984), Smith and Stulz (1985), Stulz (1990), Froot, Scharfstein, and Stein (1993), DeMarzo and Duffie (1995), and Mello and Parsons (2000) for further discussions.

${ }^{2}$ In a recent paper, Mello and Ruckes (2005) also consider how the hedging decisions of firms competing in the same product market can be interdependent. They assume a convex payoff function, which implies that the benefit from "getting ahead" is larger than the loss from "falling behind" in product market competition. This convexity also leads to heterogeneity in firms' hedging decisions.

${ }^{3}$ Fenn, Post, and Sharpe (1996) as well as all Wharton derivatives surveys show that derivative usage varies significantly across industries. Géczy, Minton, and Schrand (1997) report that the use of derivatives increased following deregulation in the gas industry.

${ }^{4}$ The latest Wharton survey reports that about $50 \%$ of nonfinancial firms in the U.S. use derivatives. Nance, Smith, and Smithson (1993) report that $62 \%$ of Fortune 500 and S\&P400 firms used derivatives in 1986. In Géczy, Minton, and Schrand (1997), 60\% of Fortune 500 nonfinancial firms used some kind of derivative securities in 1990. Simkins (2004) reports that $45 \%$ of Fortune 500 and S\&P500 nonfinancial firms use derivatives. Allayanis and Ofek (2001) report that $43 \%$ of S\&P nonfinancial firms use derivatives.

${ }^{5}$ Alternatively, one could assume that firms have exposures after earlier production decisions. For example, they may have accounts receivable or payable that are affected by exchange rate movements, or they may have entered into forward contracts with foreign sup- 
pliers or buyers at prices that are fixed in terms of some foreign currency. Mello and Ruckes (2005) present a model in which exchange rate movements affect firms' payoffs depending on the currency denomination in which debt is issued.

${ }^{6}$ In this section firms can either hedge completely or not at all. We consider partial hedging strategies in Section VI.

7 Alternatively, empire-building tendencies also may motivate managers to invest all of their cash flows.

${ }^{8}$ It has been widely argued in the trade credit literature that suppliers have considerable advantage over outside lenders in terms of information collection, bargaining power, and liquidation of the customers' assets (especially inventory).

${ }^{9}$ Recall that $P>\frac{c}{\gamma(k)}$, otherwise there would be no production. Furthermore, notice that for given $P$, it is also the case that the profit function is convex in $k$ for low values of $k$ and concave in $k$ for high values of $k$. However, the unconstrained optimal level of $k$, by virtue of second-order necessary conditions for a maximum, the profit function must be concave in $k$. Thus, financially constrained firms can operate in the convex region of their profit functions if their investment levels are substantially below the unconstrained optimum.

10 To see this in another way, define $s(k) \equiv \frac{\gamma^{\prime}(k)}{\gamma(k)^{2}}$. The concavity of $\gamma(k)$ implies that $s^{\prime}(k)<0$. It can then be shown that $\frac{\partial^{2} \Pi(k)}{\partial k^{2}}$ is positive if and only if $\frac{c}{\gamma(k)}<P<$ $c\left(\frac{1}{\gamma(k)}-\frac{s(k)^{2}}{s^{\prime}(k)}\right)$. Thus, the profit function is locally convex in $k$ for small values of $P$, and locally concave in $k$ for larger values of $P$.

11 The relevance of production flexibility for a firm's hedging decisions is demonstrated, for example, by Aabo and Simkins (2005), who show that for a sample of Danish firms 
the decision to hedge is affected by the existence of real options (the possibility to react to changes in exchange rates).

12 This follows straightaway from an application of the Envelope Theorem. The profit of a price-taking firm that faces a constant price $P$ and has a cost function $C(q)=\frac{\delta}{2} q^{2}+c q$ is $\Pi(P)=P q-\frac{\delta}{2} q^{2}-c q$. Notice that the parameter $c$ represents the intercept of the marginal cost curve. From the Envelope Theorem, $\frac{d \Pi}{d c}=-q$. Thus, the higher the profit-maximizing output, the greater the impact of a given increase in the intercept of the marginal cost curve on the profit. Since the profit-maximizing output is increasing in $P$, it follows that the benefit of a lower marginal production cost is higher the higher is the product price.

13 Please see our working paper (Adam, Dasgupta, and Titman (2006)) for a graphical proof.

${ }^{14}$ Our analysis appears to be based on particular functional forms for production and cost. As the discussion in this section shows, however, the crucial aspect of our analysis is that the profit function is convex for small $k$, which is associated with a region of increasing returns to scale (and decreasing long-run average cost). These are exactly the types of production and cost functions that are traditionally assumed in economic analysis. Thus, so long as these features are preserved under more general setups, our results should go through. One of the benefits of assuming specific functional forms is that we are able to obtain closed-form solutions.

15 This is because the volatility in the profit of an unhedged firm is due to that of $P-w$. Since these two variables covary positively, and the covariance is increasing in the number of firms that remain unhedged, the real option benefit is reduced as more firms choose not to 
hedge.

16 The value $\bar{m}^{u}$ does not exist if either (i) the right-hand side of (29) is positive for all $m^{u} \leq n$, or (ii) it is negative for $m^{u} \geq 0$. In the former case, all firms remain unhedged in equilibrium. In the latter, all firms hedge in equilibrium.

${ }^{17}$ Most heterogeneity also prevails if $n \rightarrow \infty$, that is, as markets become more competitive there will be more diversity in hedging strategies.

18 The hedged firm will shut down production if the price falls below $\alpha$. Since no production is possible if $a<\alpha$, the relevant market size is $a-\alpha$.

19 This requires that the marginal cost curves are increasing in output, that is, $\delta>0$.

20 A more precise statement for parts $2(\mathrm{a})$ and (b) is that both the bounds for the proportion of firms that do not hedge in equilibrium given in equation (31) decrease (increase) as $b$ decreases or $\delta$ increases. Similarly, a more precise statement for part 2(c) is that the lower bound in equation (31) decreases (the upper bound in equation (31) increases) as $n$ decreases.

${ }^{21}$ It is straightforward to verify from (24) that a higher $\delta$ or a lower $b$ leads to lower price volatility. To verify that they also lead to a higher expected price, differentiate the expression in equation (24) with respect to $\delta$ or $b$ and use the fact that for positive expected output, we need $(a-\alpha) n-m^{u} E(w)>0$. Notice also that the expected price decreases in $b$ and the variance increases in $b$ only if $\delta$ is strictly positive.

${ }^{22}$ We are grateful to an anonymous referee for suggesting some of these extensions.

${ }^{23}$ Details of the analysis are given in Appendix C1 and Appendix C2 of our working paper (Adam, Dasgupta, and Titman (2006)). 
${ }^{24}$ Mian (1996) studies a sample of 3,022 firms and reports that there is little evidence that existing theories can explain differences in hedging behavior. Allayannis and Ofek's (2001) empirical model explains at most $28 \%$ of the variation in the decision to hedge. Controlling for the size of the exposure substantially reduces the explanatory power of the variables for the decision to hedge. Rajagopal and Pincus' (2000) empirical model explains about $10 \%$ of the variation in the dependent variables. Haushalter (2000) documents wide variation in hedging policies in the oil and gas industry. He finds that about $50 \%$ of the firms in this industry hedge, and his regression model explains only $16 \%$ of the variation in the decision to hedge.

25 The literature uses various criteria to identify financially unconstrained firms, such as firm size, availability of bond ratings, dividend payout propensity, or the Kaplan and Zingales Index. See, for example, Almeida, Campello, and Weisbach (2004) and Kaplan and Zingales (1997).

${ }^{26}$ Note that $\frac{E w}{E w^{2}}=\frac{1}{c} \times \frac{E\left(\frac{1}{\gamma(k)}-\frac{1}{\gamma(k)}\right)}{E\left(\frac{1}{\gamma(k)}-\frac{1}{\gamma(k)}\right)^{2}}$. Thus, $\frac{E w}{E w^{2}}$ is decreasing in $c$ and the implication follows from Proposition 5.1.

${ }^{27}$ Firms with sales or debt denominated in foreign currencies are exposed to cash flow shocks due to exchange rate movements. Nain (2004) examines how the sensitivity of the industry price to exchange rate changes depends on the proportion of firms in the industry that hedge. She finds that industry price is less sensitive to foreign exchange rate movements in industries in which currency hedging is more widespread.

28 For example, for firms with $\theta>0, \frac{m^{u}}{n}>\frac{1}{2}$. Higher values of $b$ will imply higher sensitivity $\left(\frac{d P}{d w}\right)$ and lower $\frac{m^{u}}{n}$. For $\theta<0, \frac{m^{u}}{n}<\frac{1}{2}$. Higher values of $b$ will imply higher 
sensitivity and higher $\frac{m^{u}}{n}$.

${ }^{29}$ We are grateful to an anonymous referee for raising this point.

${ }^{30}$ In a recent paper, Acharya, Almeida, and Campello (2004) argue that firms enjoying a high correlation between cash flows and investment opportunities do not need to carry cash balances, and would rather pay down debt to increase debt capacity for the future. On the other hand, those that do not enjoy a high correlation will hold cash to finance future projects. 


\section{Appendix A: Proofs}

Proof of Lemma 1: The profit functions of unhedged and hedged firms given in equations

(26) and (27) are

$$
\begin{gathered}
\Pi^{u}\left(w, m^{u}\right)=\frac{\delta+2 b}{2(\delta+b)^{2}}\left(P\left(w, m^{u}\right)-w-\alpha\right)^{2} \\
\Pi^{h}\left(w, m^{u}\right)=\frac{\delta+2 b}{2(\delta+b)^{2}}\left(P\left(w, m^{u}\right)-\alpha\right)^{2} .
\end{gathered}
$$

Taking expectations and subtracting, we get

$$
E \Pi^{h}\left(w, m^{u}\right)-E \Pi^{u}\left(w, m^{u}\right)=\frac{\delta+2 b}{2(\delta+b)^{2}}\left[2 E\left[\left(P\left(w, m^{u}\right)-\alpha\right) w\right]-E\left(w^{2}\right)\right]
$$

Rewrite the equilibrium price, equation (24), as follows:

$$
\begin{gathered}
P\left(w, m^{u}\right)-\alpha=\frac{(a-\alpha)(\delta+b)+b m^{u} w}{n b+\delta+b} \\
\left(P\left(w, m^{u}\right)-\alpha\right) w=\frac{(a-\alpha)(\delta+b)}{n b+\delta+b} w+\frac{b m^{u}}{n b+\delta+b} w^{2} \\
E\left\{\left(P\left(w, m^{u}\right)-\alpha\right) w\right\}=\frac{(a-\alpha)(\delta+b)}{n b+\delta+b} E(w)+\frac{b m^{u}}{n b+\delta+b} E\left(w^{2}\right)
\end{gathered}
$$

Finally, substitute equation (A6) into equation (A3) to get

$$
\begin{aligned}
& E \Pi^{h}\left(w, m^{u}\right)-E \Pi^{u}\left(w, m^{u}\right) \\
= & \frac{(\delta+2 b)}{2(\delta+b)^{2}}\left[\frac{2(a-\alpha)(\delta+b)}{n b+\delta+b} E(w)+\frac{2 b m^{u}}{n b+\delta+b} E\left(w^{2}\right)-E\left(w^{2}\right)\right]
\end{aligned}
$$




\section{Industry Mark-Ups}

(Value of sales + change in iventories - payroll - cost of materials) I (Value of sales + change in iventories)

Source: Allayannis and Weston (1999)

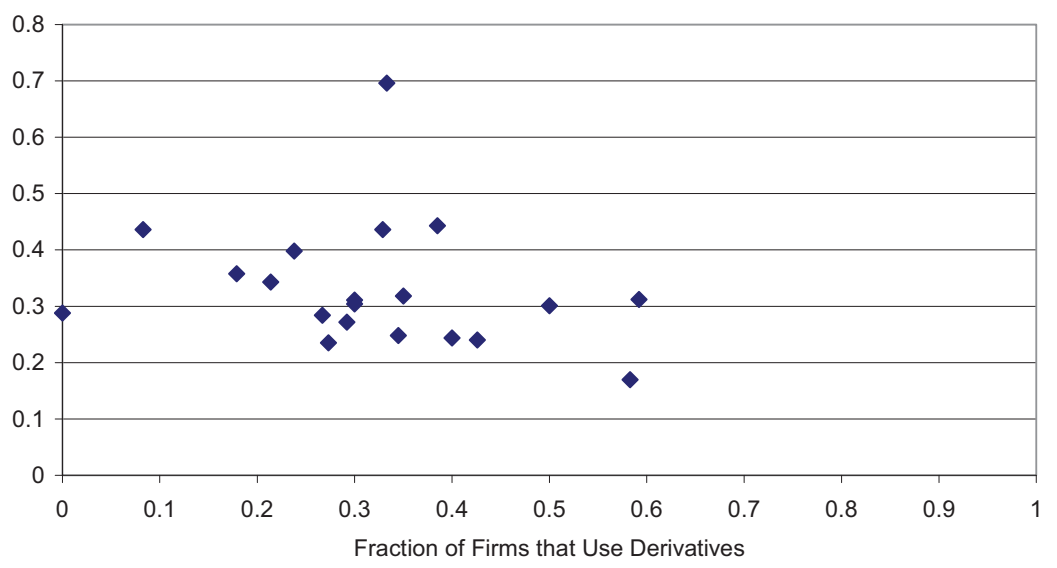

\section{Number of Firms in Industry (Sample)}

Source: Geczy, Minton and Schrand (1997)

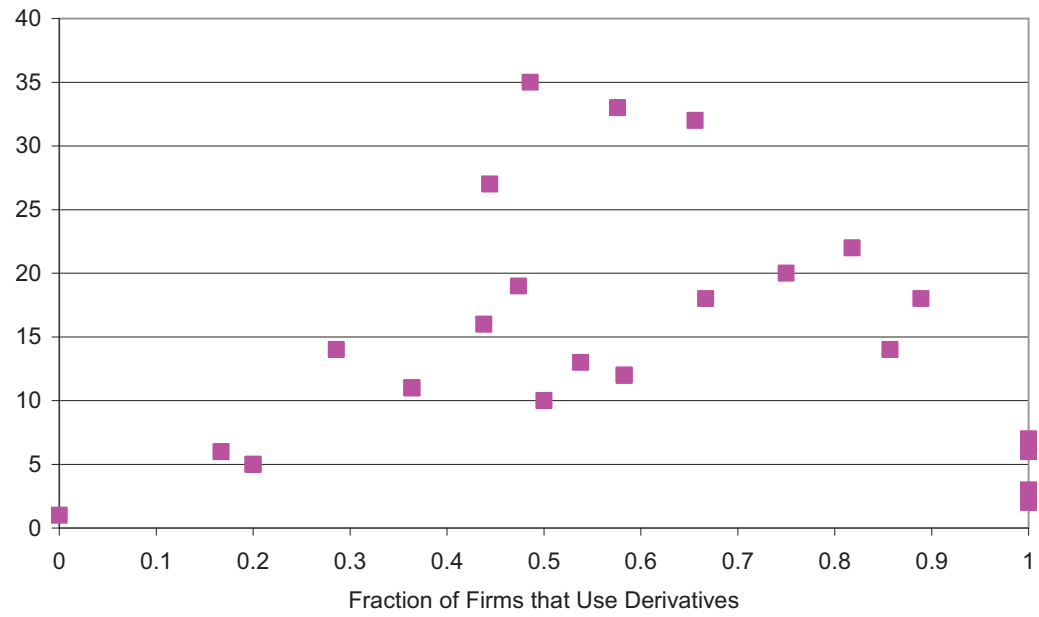

Figure 1. Empirical relations between the fraction of firms

that hedge and industry characteristics. 
The next proof uses the following lemma:

LEMMA A1: (i) $E \Pi^{h}\left(w, m^{u}\right)$ is increasing in $m^{u}$. (ii) $E \Pi^{u}\left(w, m^{u}\right)$ is decreasing in $m^{u}$ for $m^{u}<\frac{n+1}{2}+\bar{m}^{u}$, where $\bar{m}^{u}$ is the real number value of $m^{u}$ for which the right-hand side of (29) is zero.

Proof: (i) From equation (A2), we have

$$
E \Pi^{h}\left(w, m^{u}\right)=\frac{\delta+2 b}{2(\delta+b)^{2}} E\left(P\left(w, m^{u}\right)-\alpha\right)^{2} .
$$

Using (A4) to substitute for $E\left(P\left(w, m^{u}\right)-\alpha\right)^{2}$, we get

$$
E \Pi^{h}\left(w, m^{u}\right)=\frac{\delta+2 b}{2(\delta+b)^{2}}\left[c+\frac{b^{2}\left(m^{u}\right)^{2}}{(n b+\delta+b)^{2}} E\left(w^{2}\right)+\frac{2(a-\alpha)(\delta+b) b m^{u}}{(n b+\delta+b)^{2}} E(w)\right]
$$

where $c$ is a constant. This is increasing in $m^{u}$.

(ii) From equation (A1), we have

$$
E \Pi^{u}\left(w, m^{u}\right)=\frac{\delta+2 b}{2(\delta+b)^{2}} E\left(P\left(w, m^{u}\right)-w-\alpha\right)^{2} .
$$

Using (A4) to substitute for $E\left(P\left(w, m^{u}\right)-\alpha\right)^{2}$ and using (A6), we get

$$
\begin{aligned}
E \Pi^{u}\left(w, m^{u}\right)= & \frac{\delta+2 b}{2(\delta+b)^{2}}\left[c+\frac{b^{2}\left(m^{u}\right)^{2}}{(n b+\delta+b)^{2}} E\left(w^{2}\right)+\frac{2(a-\alpha)(\delta+b) b m^{u}}{(n b+\delta+b)^{2}} E(w)\right. \\
& \left.+E\left(w^{2}\right)-\frac{2(a-\alpha)(\delta+b)}{n b+\delta+b} E(w)-\frac{2 b m^{u}}{n b+\delta+b} E\left(w^{2}\right)\right] .
\end{aligned}
$$

Again, here $c$ is a constant. Treating $m^{u}$ as a real number and differentiating with respect

to $m^{u}$, we get

$$
\begin{aligned}
\frac{d E \Pi^{u}\left(w, m^{u}\right)}{d m^{u}}= & -\frac{b(\delta+2 b)}{2((n+1) b+\delta)(\delta+b)^{2}}\left[2 E\left(w^{2}\right)-\frac{2(a-\alpha)(\delta+b)}{n b+\delta+b} E(w)-\frac{2 b m^{u}}{n b+\delta+b} E\left(w^{2}\right)\right] \\
= & -\frac{b(\delta+2 b)}{2((n+1) b+\delta)(\delta+b)^{2}}\left[E\left(w^{2}\right)-\frac{2 b\left(m^{u}-\bar{m}^{u}\right)}{n b+\delta+b} E\left(w^{2}\right)\right. \\
& \left.+\left\{E\left(w^{2}\right)-\frac{2(a-\alpha)(\delta+b)}{n b+\delta+b} E(w)-\frac{2 b \bar{m}^{u}}{n b+\delta+b} E\left(w^{2}\right)\right\}\right] .
\end{aligned}
$$


Notice that the expression within curly brackets is zero, from the definition of $\bar{m}^{u}$. Thus, the bracketed expression is positive when $1>\frac{2 b\left(m^{u}-\bar{m}^{u}\right)}{n b+\delta+b}$. Hence, the result follows.

Proof of Proposition 2: First Part. If an integer $m^{u}$ exists such that the right-hand side of (29) is zero, then none of the remaining $n-m^{u}$ firms that are hedged have any incentive to deviate and become unhedged, since from Lemma A1 $E \Pi^{u}\left(w, m^{u}+1\right)<E \Pi^{u}\left(w, m^{u}\right)=E \Pi^{h}\left(w, m^{u}\right)$ at this value of $m^{u}$. Similarly, none of the $m^{u}$ firms that are currently unhedged have any incentive to deviate and become hedged, since $E \Pi^{h}\left(w, m^{u}-1\right)<E \Pi^{h}\left(w, m^{u}\right)=E \Pi^{u}\left(w, m^{u}\right)$ from Lemma A1. Thus, the necessary and sufficient conditions for a SPNE are satisfied for $m^{u}$.

Second Part. (a) If $E \Pi^{u}\left(w, m_{2}^{u}\right)<E \Pi^{h}\left(w, m_{1}^{u}\right)$, then given that $m_{1}^{u}$ firms are unhedged, there is no incentive for any of the remaining $n-m_{1}^{u}$ firms that are hedged to become unhedged. Again, since $E \Pi^{h}\left(w, m_{1}^{u}-1\right)<E \Pi^{h}\left(w, m_{1}^{u}\right)<E \Pi^{u}\left(w, m_{1}^{u}\right)$ (where the first inequality follows from Lemma A1 and the second from the definition of $m_{1}^{u}$ ), none of the currently unhedged firms has any incentive to deviate and become hedged. Thus, the necessary and sufficient conditions for a SPNE are satisfied for $m_{1}^{u}$.

(b) If $E \Pi^{u}\left(w, m_{2}^{u}\right)>E \Pi^{h}\left(w, m_{1}^{u}\right)$, then none of the $m_{2}^{u}$ unhedged firms has any incentive to deviate and become hedged, since its payoff is $E \Pi^{h}\left(w, m_{1}^{u}\right)<E \Pi^{u}\left(w, m_{2}^{u}\right)$. Similarly, none of the remaining $n-m_{2}^{u}$ firms that are hedged has any incentive to deviate and become unhedged, since $E \Pi^{u}\left(w, m_{2}^{u}+1\right)<E \Pi^{u}\left(w, m_{2}^{u}\right)<E \Pi^{h}\left(w, m_{2}^{u}\right)$, where the first inequality follows from Lemma A1 and the second from the definition of $m_{2}^{u}$. Thus, the necessary and sufficient conditions for a SPNE are satisfied at $m_{2}^{u}$. 
Proof of Proposition 6: We have

$$
\frac{d P}{d w}=\frac{n b\left(m^{u} / n\right)}{n b+\delta+b}=\frac{n b\left(\frac{1}{2}+\frac{b+\delta}{n b} \theta\right)}{n b+\delta+b}=\frac{\frac{n b}{2}+(b+\delta) \theta}{n b+\delta+b}=\frac{\frac{n b}{2(\delta+b)}+\theta}{\frac{n b}{\delta+b}+1} .
$$

It is easy to verify that the last term is increasing in $\frac{n b}{b+\delta}$ if and only if $\frac{1}{2}>\theta$. However, from the definition of $\theta$ (equation (32)), it is clear that since $E(w)>0$, this condition must hold. The result easily follows. 


\section{Appendix B: The Proportion of Unhedged Firms if the Industry has $m^{u c}$ Unconstrained Firms}

To demonstrate this result, let the equilibrium investment level of an unconstrained firm in state $w$ be denoted by $k^{u c}(w)$. Thus, the unconstrained firms have the following cost function:

$$
C^{u c}(q)=\frac{\delta}{2} q^{2}+\frac{c}{\gamma\left(k^{u c}(w)\right)} q=\frac{\delta}{2} q^{2}+\alpha^{\prime}(w) q
$$

where

$$
\alpha^{\prime}(w) \equiv \frac{c}{\gamma\left(k^{u c}(w)\right)} .
$$

Notice that since the unconstrained firms invest more when $w$ is higher, $\alpha^{\prime}(w)$ is decreasing in $w$. Further, $\alpha^{\prime}(w)$ depends on $n, m^{u}$ (the number of firms that remain unhedged), as well as $m^{u c}$, the number of unconstrained firms. We assume that $k^{u c}(w)>\bar{k}$ for all $w$, which is equivalent to $\alpha>\alpha^{\prime}(w)$ for all $w$, that is, the unconstrained firms have a lower intercept of the marginal cost curve than the hedged firms for all realizations of the cash flow shocks.

Proceeding as in the proof of Lemma 1 and Proposition 3, one can show that the proportion of firms that remain unhedged is implicitly given by

$$
\frac{m^{u}}{n}=\frac{1}{2}+\left(\frac{1}{n}+\frac{\delta}{n b}\right)\left[\frac{1}{2}-(a-\alpha) \frac{E(w)}{E\left(w^{2}\right)}\right]+\frac{E\left(\left(\alpha-\alpha^{\prime}(w)\right) w\right)}{E\left(w^{2}\right)}\left(\frac{m^{u c}}{n}\right) .
$$

Since $\alpha^{\prime}(w)$ is decreasing in $w$, and by assumption, $\alpha-\alpha^{\prime}(w)>0$, we have $E\left(\left(\alpha-\alpha^{\prime}(w)\right) w\right)=$ $\operatorname{Cov}\left(\left(\alpha-\alpha^{\prime}(w), w\right)+E\left(\alpha-\alpha^{\prime}(w)\right) E(w)>0\right.$. Thus, comparing the above equation with equation (31), it immediately follows that for any $m^{u c}>0$, the proportion of firms in the industry that remain unhedged is higher compared to the situation in which there are no unconstrained firms, i.e., $m^{u c}=0$. Notice that equation (B3) implies that if a given number 
of firms in the industry become unconstrained, then the number of firms that choose to remain unhedged will not only increase as a proportion of the constrained firms, but also as a proportion of all firms in the industry. 